\title{
Neurobehavioural changes in a patient with bilateral lesions of the globus pallidus
}

\author{
R. Haaxma 1 , T.W. Robbins ${ }^{2}$, M. James ${ }^{3}$, W.H. Brouwer ${ }^{1}$, J.G. Colebatch ${ }^{4,5}$ \\ and C.D. Marsden ${ }^{4}$ \\ 'Department of Neurology, University Hospital Groningen, The Netherlands, ${ }^{2}$ Department \\ of Experimental Psychology, University of Cambridge, ${ }^{3}$ Department of Psychology and \\ ${ }^{4}$ University Department of Neurology, The National Hospital for Neurology and \\ Neurosurgery, Queen Square and ${ }^{5}$ MRC Cyclotron Unit, Hammersmith Hospital, \\ London, UK \\ Correspondence to: R. Haaxma, Department of Neurology, University Hospital Groningen, \\ Broerstraat 5, POB 72, 9700 AB Groningen, The Netherlands
}

\begin{abstract}
This study has characterized the long-term neurobehavioural changes in a woman who, following the intake of an unidentified substance, sustained subtotal bilateral lesions of the globus pallidus and small lesions at selective sites adjacent to it. Associated with these lesions was a significantly reduced blood flow in multiple frontal cortical regions, most prominently in area 10, the anterior cingulate and the supplementary motor cortex. Her cognitive deficits were generally consistent with those found in patients with frontal lobe dysfunction but some deficits, i.e. in visual memory and learning, were more compatible with temporal lobe dysfunction. Incapacitating personality or obsessive compulsive changes as reported by others with similar lesions were absent and she could live independently. The cognitive changes are consistent with the view that the globus pallidus has important functions in mediating how internal representations of stimulus input are converted into various forms of action, for example, in planning solutions to problems and in working memory.
\end{abstract}

Keywords: Bilateral lesion - Cognitive deficits - Globus pallidus

\section{INTRODUCTION}

Although there have been extensive investigations into the nature of the cognitive deficits resulting from diseases of the basal ganglia (BG), there has been relatively little analysis of the effects of well-defined lesions of elements of the BG. Laplane et al. $(1984,1989)$ described a lack of initiative, mental slowing, and obsessive-compulsive behaviour in a number of cases that had sustained bilateral globus pallidus (GP) lesions and showed frontal hypometabolism using positron emission tomography (PET). There were deficits on a number of standard tests of frontal lobe function, including the Wisconsin Card Sorting Test and verbal fluency. Strub (1989) described a single similar case who displayed several frontal signs on clinical examination, including deficits in cognitive function.

This report deals with the cognitive deficits in a single case, patient $\mathrm{A}$, who had large subtotal bilateral lesions of the GP and some other small lesions, and who we have studied in considerable detail using not only standard tests but also a sophisticated battery of tests designed to be sensitive to frontal lobe damage (Downes et al., 1989; Owen et al., 1990, 1991, 1992). These were supplemented by other tests that we have shown to be sensitive to the memory and learning deficits seen in patients with Alzheimer's and Parkinson's diseases (Sahakian et al., 1988).

\section{CASE REPORT}

Patient A, a female born in 1955, became in December 1982 acutely encephalopathic a few hours after oral ingestion of an unidentified substance. On admission 2 days later she was obtunded and confused with signs of autonomic dysfunction including fever, hypertension, profuse sweating, and tachycardia. She reacted to simple commands and uttered an occasional string of words. There was a pendular nystagmus. A striking flaccidity of the limb musculature was noted. She was able to lift her arms against gravity and to perform a reasonable finger to nose test but could only just lift her legs from the bed and did so when supported under the heels. The plantar responses were flexor on both sides. A screening for opioids, barbiturates, benzodiazepines, amphetamine and alcohol was negative. A tentative diagnosis of WernickeKorsakoff encephalopathy was made and she received large doses of vitamin B. On the ninth hospital day an electroencephalogram (EEG) demonstrated symmetrical 
bilateral slowing. The symptoms receded over the first 3 weeks, by which time she was again walking independently. However, locomotion was grossly abnormal and there were uncontrolled falls. After a total of 3 months she was discharged home. At that time a repeat EEG demonstrated a normal basic trace and sporadic bilateral low voltage alpha-theta paroxysms. A computed brain tomogram (CT) showed bilateral areas of low attenuation in the pallidal region.

One year after this event she was first seen at our hospital in Groningen. On examination she was alert, orientated and appeared to have an average intellect. Most striking was her gait which was characterized by an extension bias in the knees and hips and abnormal push-over reactions backward. There was some slowness of the fastest movements of the arms and hands. These deficits are fully described elsewhere (Haaxma et al., submitted).

\section{Life history and personality}

She was the youngest child of working parents, with two elder sisters, and was reported to be difficult and disruptive during childhood. She failed to finish high school and dropped out at 17 to get a job. She worked as a saleswoman in several shops and at the reception desk of a hotel. In her twenties she started to sniff and smoke heroin, a habit that persisted for 7 years. She stopped the habit by entering a detoxification program with methadone a year before the acute event. In the same period she began to abuse alcohol periodically, for which she was given antabuse medication. Following her recovery she has abstained from taking drugs. At present she is generally good natured and does not display any lack of initiative or report any obsessive or compulsive behaviour. However, occasionally subtle signs of lack of insight, childishness and negativism have been observed during the periods of investigation. Her current activities include work as a volunteer taking responsibility for a simple type of accountancy on behalf of refugees. She has joined a choir and obtained a driver's licence. She is on social welfare and she lived on her own until she married 7 years after her illness began. On a standardized Dutch Personality Questionnaire (Luteyn et al., 1985) she scored high on rigidity, anxiety, depression, and lability and low on self-esteem. On the Maudsley Obsessive Compulsive Inventory (Rachman and Hodgson, 1980) her score was 6 which was slightly higher than a non-neurotic control group but was well below the obsessionals (18.86, S.D. 4.92).

\section{NEUROPSYCHOLOGICAL FINDINGS}

\section{Psychometric testing}

The patient has had psychological investigations in London and Groningen. When tested in London in May 1989, on the Performance Scale of the WAIS (Wechsler,
1955), she obtained a score of 93 . Individual subtests were scored at the average level (Picture Completion and Picture Arrangement) and the dull average level (Block Design). She was able to repeat four digits forwards and only two backwards. No other verbal subtests were administered at that time as English is not her first language. However, the Verbal Scale of the WAIS was administered in Dutch in Groningen in September 1990, when she obtained a verbal I.Q. of 100. On the Dutch version of the National Adult Reading Test (cf. Nelson, 1982), her estimated premorbid I.Q. was 104. By comparison with her test results in January and March 1983 (verbal I.Q. 91, 99; performance I.Q. 96, 110), there was no evidence of any systematic change in her performance on formal intellectual tests over this period. She was tested in May 1989 on a non-verbal reasoning test (Raven's Standard Progressive Matrices; Raven, 1958) and scored at the bottom of the dull average range. On the Advanced Progressive Matrices (set 1 ) she scored similarly at the dull average level for her age (3/12).

On tests of visual perception there was no evidence of any impairment. For example, she scored $19 / 20$ on the Unconventional Views Test (Warrington and Taylor, 1973); 18/20 on Incomplete Letters (Warrington and James, 1967a); and 23/30 on the Silhouettes Test (Warrington and James, 1988). On the Dot Centre test of spatial skills (Warrington and James, 1988) her performance was error free.

Her memory was tested on several occasions in both Groningen and London during the period 1984-1990. In February 1984 she was tested with the "15 words test" (Deelman and Saan, 1990), a Dutch test of auditory free recall. She scored at the low normal range with regard to acquisition, while her retention of the learned words after a delay was normal. She was also tested at this time on the "Oxford Recurring Faces Test" (Newcombe, unpublished; Deelman and Saan, 1990), where she correctly recognized 50 out of 60 faces, a low normal score. In February and September 1984 and March 1986 she was given the Benton Visual Retention test (Benton and Van Allen, 1986). Her performance was impaired on all three occasions.

A similar pattern of deficits resulted when she was tested in London in May 1989. On the Warrington Recognition Memory Tests (Warrington, 1984), her performance on the verbal version was relatively weak (43/50, dull average), but taking into account the fact that the stimuli were not in her native language this level of attainment was judged to be satisfactory. However, there was evidence of a visual memory deficit for faces, as she scored only $37 / 50$ on the visual version of the Recognition Memory Test, which is at the borderline defective level.

Taken together, her performance on these various tests, which encompass digit span, verbal and visual learning 


\begin{tabular}{lccc}
\hline & Mrs A & $\begin{array}{c}\text { Frontal lesion } \\
\text { patients }(n=26) \\
\text { (mean age 43.0) } \\
\text { Mean (S.D.) }\end{array}$ & $\begin{array}{c}\text { Controls } \\
(n=26) \\
\text { (mean age 44.5) } \\
\text { Mean (S.D.) }\end{array}$ \\
\hline Initial thinking & & & \\
time (s) & & & $3.12(2.9)$ \\
2 move & 1.63 & $3.15(2.2)$ & $9.45(8.0)$ \\
3 move & 15.11 & $13.67(13.0)$ & $8.06(4.2)$ \\
4 move & 9.76 & $12.57(10.9)$ & $11.56(7.0)$ \\
5 move & 9.76 & $14.06(13.1)$ & $0.17(0.9)$ \\
Subsequent thinking & & & $0.16(0.9)$ \\
time (s) & & & $1.95(0.4)$ \\
2 move & 2.40 & $0.24(0.3)$ & $1.35(0.4)$ \\
3 move & 1.51 & $1.34(0.7)$ & $2.39(0.6)$ \\
\hline move & 7.71 & $2.32(0.4)$ & \\
\hline move & 7.34 & & \\
\hline
\end{tabular}

and memory and tests of recognition, as well as recall, suggests a consistent, though mild, deficit that extends across several modalities of testing. On tests thought to be sensitive to frontal lobe dysfunction, her performance was impaired when tested in Groningen in September 1990. Her verbal fluency (in Dutch) was inconsistent. For example, she produced 23 animal names in 1 min but only 12 words beginning with the letter " $S$ " and seven with the letter "A". She was only able to attain two categories on the modified Wisconsin Card Sorting Test (WCST; Nelson, 1976) and made 25 errors, nine of which were perseverative.

\section{Experimental computerized tests}

These tests were mainly taken from the three CANTAB batteries; Planning and Working Memory; Attention; and Visual Memory. The tests of spatial span, spatial working memory and the Tower of London planning task were all taken from the Planning and Working Memory battery (see Owen et al., 1990). The attentional set-shifting task was taken from the Attentional battery (Downes et al., 1989) and the tests of visual memory and learning from the Visual Memory battery (Sahakian et al., 1988). The computerized tests of visuospatial construction ability (Owen et al., in preparation) comprised three main stages, each with a maximum of four problems. In each stage, the subject was required to "build" a two-dimensional pattern from its component elements. In the first stage the elements did not require spatial transformation, whereas in the second stage the elements had to be mirror image transformed and in the third stage the elements had to be rotated through $180^{\circ}$.

\section{Spatial span}

Her spatial span was 4 , as compared with a mean (S.D.) value of $5.5(1.35)$ for a group of 26 normal subjects (of average age 44.6 and mean NART I.Q. equivalent 109).

\section{Spatial working memory}

For between-search errors her performance was error-free up to and including the level of four boxes. However, her performance was consistently poor at six and eight boxes, with 26 and 34 errors, respectively. By comparison with both the group of normal control subjects and patients with frontal lobe lesions, these are inferior scores [six boxes: mean error scores (S.E.) controls, 6 (1); frontals 15 (1); eight boxes: mean error scores (S.E.) controls, 20 (2); frontals 28 (2)]. Within-search errors are rare in controls, but her performance (of three and four errors at the six and eight box levels) was again comparable with that of patients with frontal lobe damage. She showed no evidence of a consistent search strategy (score 24) as compared with mean (S.E.) scores for the control [14.1 (1.1)] and the frontal groups [17.6(0.9)].

\section{Tower of London planning task}

She performed badly on this task in terms of both accuracy and latency and solved $5 / 12$ problems in the minimum numbers of moves, compared with 7.3/12 for frontal subjects and $8.6 / 12$ for controls. She was able to complete $10 / 12$ problems in the maximum number of moves but made a large number of invalid responses in comparison with controls who make hardly any. The pattern of her latency of thinking resembled that of patients with frontal lobe deficits (Owen et al., 1990). As in previous studies we controlled for possible motor disability by subtracting the latencies in a yoked control test to provide measures of true thinking time. Our calculations were based on all of her solutions, whether correct or not. Whereas there was no consistent slowing of thinking prior to the first move, she did take significantly longer to consider the problems 
subsequent to her initial move (see Table I). In fact, her scores were not only outside the range for control subjects, but also significantly worse than for patients who had received neurosurgery of the frontal lobes.

\section{Attentional set shifting task}

On the test of attentional shifting she was able to reach the extradimensional shift stage, but failed to reach criterion after 50 trials. By comparison, only two out of 22 normal subjects (mean age 27, S.E.M. 1.8; mean NART I.Q. estimate 109) failed the test. At earlier stages, she showed particular difficulty at the compound discrimination stages, when irrelevant stimuli are introduced. She was able successfully to make the intra-dimensional shift and the reversal. This pattern resembles that seen following frontal lobe damage and basal ganglia disorders (Owen et al., 1990, 1991, 1992; Downes et al., 1989; Robbins et al., 1992).

\section{Pattern and spatial recognition memory}

Scores on the visual pattern and spatial recognition tests were 17/24 and 13/20, respectively. In comparison with 46 normal subjects (mean age 57.2; mean NART I.Q. equivalent 117.5 ) these scores are below the 10th percentile.

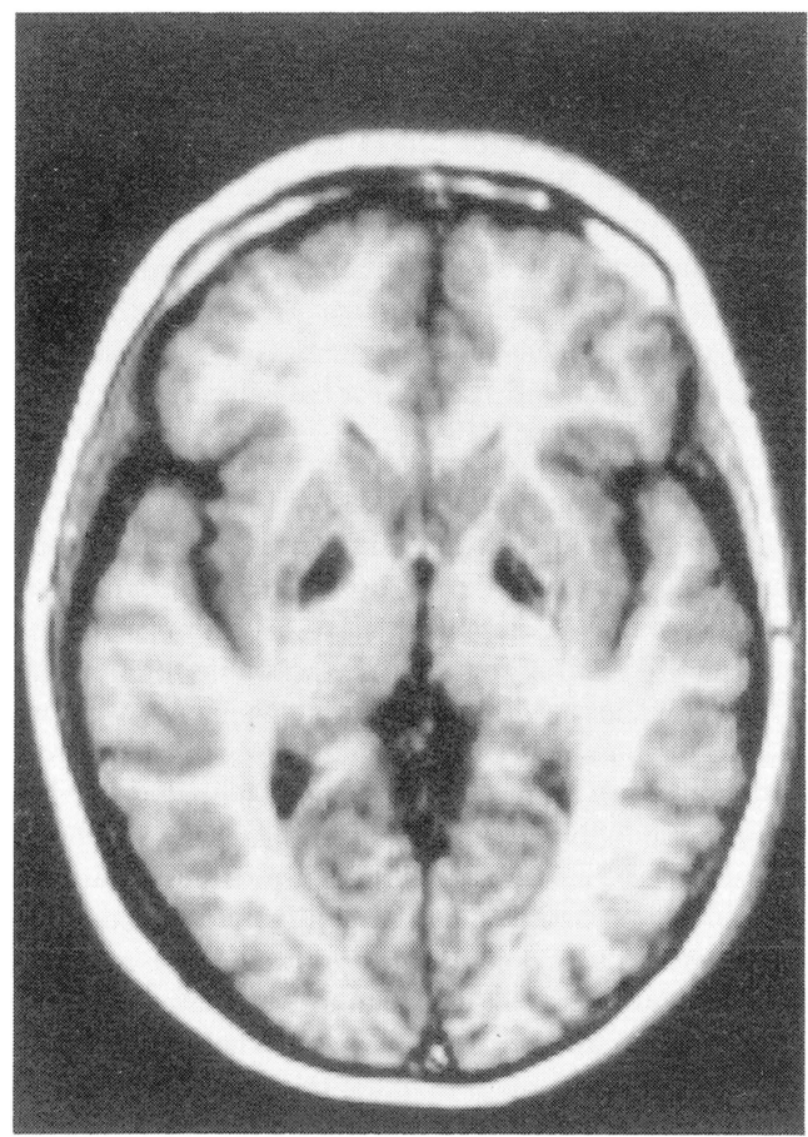

\section{Simultaneous and delayed matching to sample}

Her performance was error free on the perceptual matching part of the test and also at $0 \mathrm{~s}$ delay. However, she scored only $60 \%$ on the trials with delays greater than $0 \mathrm{~s}$ which is approximately at the 5 th percentile of the control group. The pattern of her errors suggested that some processing of the stimuli was occurring, as she made only one distractor error, but correctly chose the colours of the sample stimulus four times and the shapes once from the matching stimuli.

\section{Pattern location paired associates learning}

Her performance on three items was perfect, but she failed the test at six items, making 41 errors over 10 trials. Although she correctly located each of the six stimuli at least once, her best score, attained on the last trial, was four correct out of six, indicating considerable inconsistency of retrieval. Her failure to attain criterion for six items within the 10 trials allowed is outside the range of our control group and indicates a major deficit in visuospatial, paired associates learning.

\section{Visuospatial constructional ability}

In the basic constructional task she performed satisfactorily, but was unable successfully to perform mirror

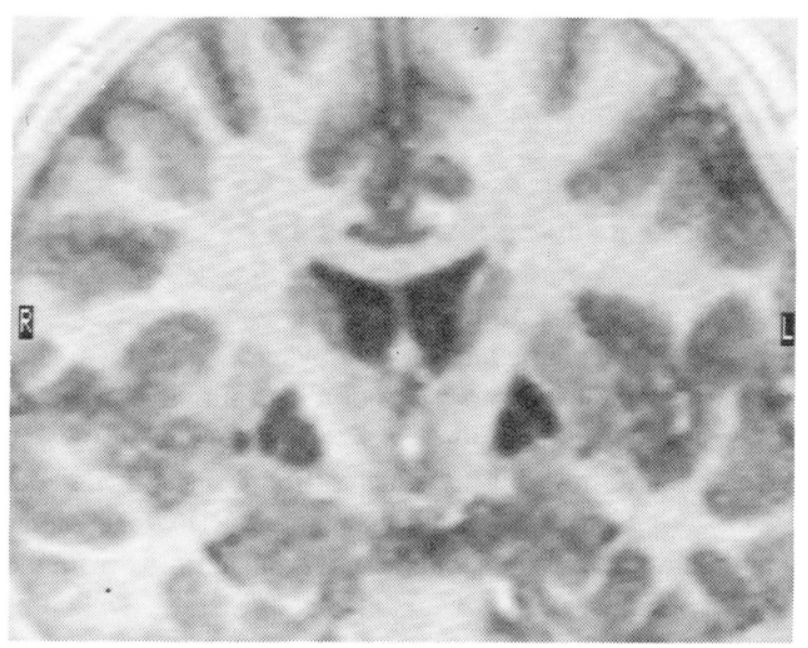

FIG. 1. Axial (A) and coronal (B) inversion recovery (T1) MRI showing areas of low signal intensity in the region of the GPi and GPe bilaterally approximately above the level of the anterior commissure (B), sparing some tissue in the rostral pole of the GP (A). Areas of abnormal signal are also visible in the outer rim of the ventral and posterior putamen bilaterally. 
TABLE II. Resting flow abnormalities

\begin{tabular}{|c|c|c|c|c|}
\hline Area & $\begin{array}{l}\text { Vertical extent } \\
(\mathrm{mm})\end{array}$ & Coordinates & $\begin{array}{l}\text { Controls } \\
(n=6)\end{array}$ & Patient \\
\hline \multicolumn{5}{|l|}{ Frontal } \\
\hline \multicolumn{5}{|l|}{ Dorsolateral prefrontal } \\
\hline$R(3)$ & +20 to +32 & $+37,+32,+24$ & 55.1 & 48.5 \\
\hline$L(6)$ & +20 to +44 & $-45,+13,+30$ & 47.6 & 42.8 \\
\hline Cingulate/SMA (4) & +36 to +48 & $-3,+13,+42$ & 64.3 & 54.5 \\
\hline R. rolandic (3) & +32 to +40 & $+35,-13,+36$ & 56.0 & 51.0 \\
\hline L. premotor (1) & - & $-32,+8,+44$ & 56.8 & 50.5 \\
\hline R. area $8(1)$ & - & $+28,+20,+44$ & 55.8 & 51.5 \\
\hline \multicolumn{5}{|l|}{ Other } \\
\hline \multicolumn{5}{|l|}{ Sup. temp. gyrus } \\
\hline $\mathrm{R}(4)$ & -4 to +8 & $+49,+1,+2$ & 56.3 & 49.9 \\
\hline L (3) & -8 to +8 & $-56,+1,+4$ & 37.0 & 32.5 \\
\hline L. putamen (3) & -4 to +4 & $-27,-6, \quad 0$ & 67.8 & 63.3 \\
\hline L. area $39(4)$ & +16 to +28 & $+50,-68,+22$ & 32.6 & 28.3 \\
\hline L. area $40(1)$ & - & $-48,-40,+36$ & 47.5 & 46.0 \\
\hline
\end{tabular}

Significant sites of reduced flow in the resting state identified by pixel $z$ score (see text). All values represent the mean of two observationsthe number of individual sites within a single area is given in brackets. Coordinates are given in $\mathrm{mm}$ and refer to the scheme of Talairach and Tournoux (1988) - the first in the sagittal plane (positive = right), the second in the coronal (positive = anterior) and the final, height above the intercommissural plane. The values quoted are the mean of the individual sites when multiple. Flow is given as $\mathrm{ml} / 100 \mathrm{ml} / \mathrm{min}$, adjusted to give a global flow of 50 for all subjects. Most sites of significant flow reduction lay within the (pre)frontal lobes. R, right; L, left; sup. temp., superior temporal; SMA, supplementary motor area.

image and rotational transformations. She correctly completed only $1 / 5$ on the former test and $0 / 5$ on the latter, compared with mean scores of a group of 17 controls of $3 / 5$ and $2.4 / 5$, respectively. In terms of total moves taken on each of the three sets of problems, patient A's scores were 5.4, 7.6 and 8.00 , compared with control means (S.D.) of 5.34 (0.7), 6.44 (1.1) and 6.81 (0.7). This confirms the conclusion that she was unimpaired on simple visuospatial constructions, but markedly impaired on more complex aspects. Her latencies both to initiate and complete the problems were not significantly different from the controls.

\section{P300}

The latency of this positive cerebral potential occurring $300 \mathrm{~ms}$ or more after a psychologically meaningful stimulus is considered a correlate of the perceptual component of reaction time (Pritchard, 1981; Coles et al., 1985). It was compared with those of an age- and educationmatched control group $(n=8)$ in a visual oddball experiment. The peak latency was $370 \mathrm{~ms}$ which was within the normal range (control group mean \pm S.D.: $409 \pm 41 \mathrm{~ms}$ ).

\section{BRAIN IMAGING FINDINGS}

\section{Magnetic resonance imaging (MRI)}

The MRI scans (Fig. 1) showed subtotal lesions of both segments of the GP bilaterally sparing the most anterior portions. Also there were small lesions bilaterally in the posteroventral putamen and adjacent white matter, laterally within the right amygdala and the right substantia nigra.

\section{${ }^{18} \mathrm{~F}-6$-Fluorodopa scan (for methods see Brooks et al., 1990)}

Quantitative analysis showed a reduced striatal ${ }^{18} \mathrm{~F}$-dopa uptake bilaterally, affecting the putamen more than the caudate nuclei. Influx $K_{\mathrm{i}}$ values were: left caudate 0.0084 , right caudate 0.0087 (normal mean \pm S.D.: $0.0107 \pm$ 0.0019 ), left putamen 0.0045 , right putamen 0.0044 (normal mean \pm S.D.: $0.0098 \pm 0.0011)$. These values are at the upper end of the range seen in Parkinson's disease (mean caudate 0.0090 , S.D. 0.0021 ; mean putamen 0.0047, S.D. 0.0010). The mesial frontal ${ }^{18} \mathrm{~F}$-dopa uptake $\left(K_{\mathrm{i}}\right.$ of 0.0010$)$ was also about $50 \%$ of the normal mean value $(0.0018 \pm 0.0010)$.

${ }^{15} \mathrm{O}_{2}$ cerebral blood flow study (for methods see Friston et al., 1989, 1991; Lammertsma et al., 1990) Images of cerebral blood flow (CBF) were collected with the patient at rest and compared with those of six normal subjects scanned under similar conditions. Overall CBF lay within the normal range. Flow defects were visible on inspection at sites corresponding to the lenticular nuclei bilaterally. A pixel-based analysis of regional CBF detected multiple sites of significantly reduced flow which were identified using the stereotaxic atlas of Talairach and Tournoux (1988) (Table II). The most extensive areas of 


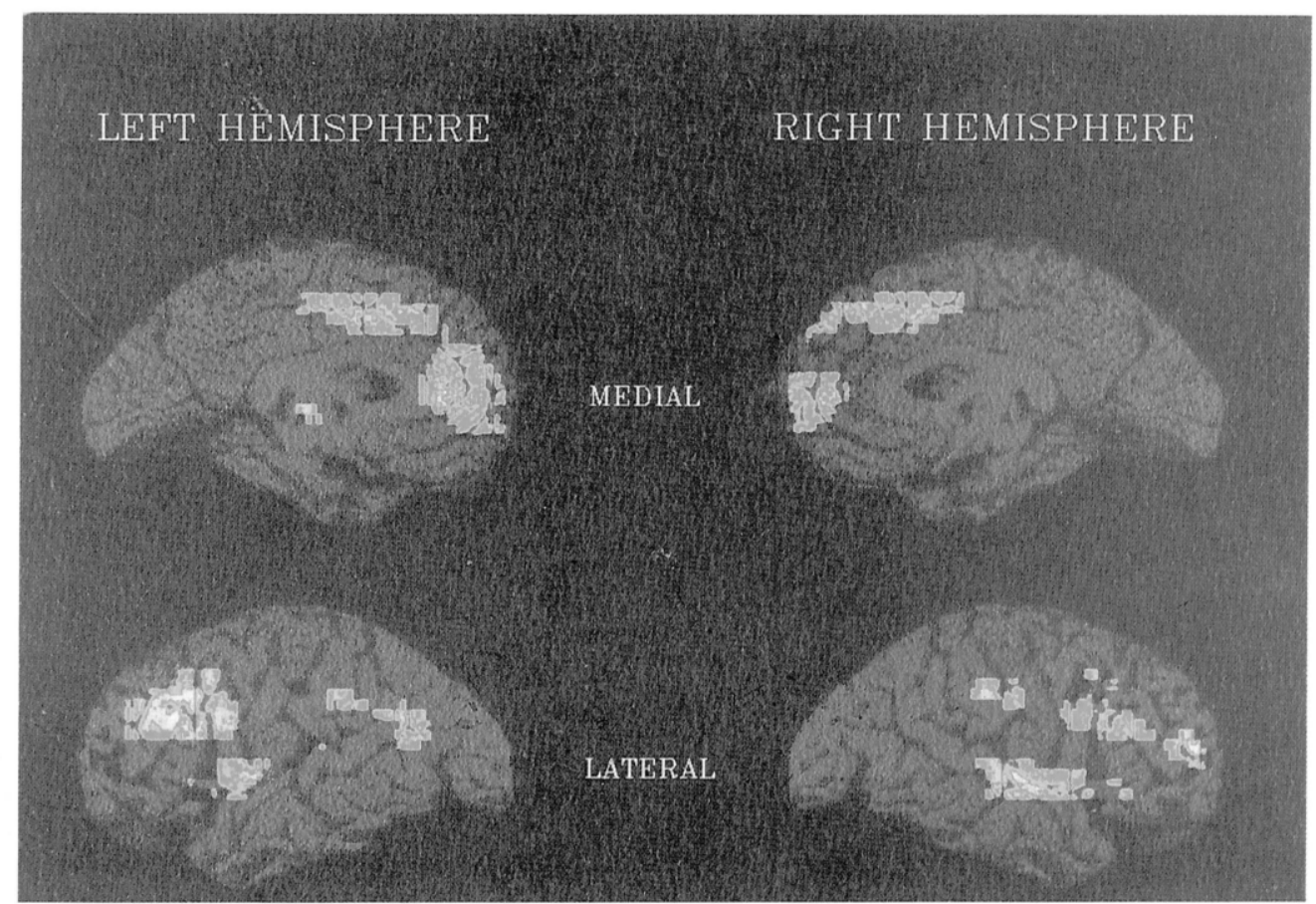

FIG. 2. 1502 PET study. Pictorial representation of the comparison of patient's resting blood flow images with those of six normal volunteers. Regions of significantly reduced blood flow ( $z$ score: corrected $p<0.05$ ) shown in red (the most significant areas are in white) are projected onto four views of the two cerebral hemispheres. The upper half shows views from the medial aspect. The lower half shows views from the lateral aspect. The areas of reduced flow were predominantly in the medial and dorso-lateral parts of the frontal lobes.

reduced flow lay bilaterally within area 10 (average reduction 14\%) and the cingulate gyrus (average reduction $13.5 \%$ ), but there were also sites of significantly reduced flow within areas $44,46,8$ and 9 bilaterally. There were single sites of reduced flow in the left premotor cortex $(-11 \%)$, medial area $6(-16 \%)$ and right sensorimotor cortex $(-9 \%)$. Other sites of significantly reduced flow were present in left area $39(-8 \%)$ and the superior temporal gyri (L $-14 \%, \mathrm{R}-13 \%)$ (Fig. 2). Flow within the thalamus was not significantly altered.

\section{DISCUSSION}

This study has characterized the long-term neuropsychological deficits in a woman who sustained neartotal bilateral lesions of the GPi and GPe and small lesions at selective sites adjacent to it following a toxic encephalopathy. The GP lesions appeared to have spared the most anterior and the subcommissural portions. From the evidence of the PET investigations there was a moderate reduction of the striatal and mesial frontal dopamine level and a significantly reduced blood flow in multiple frontal cortical regions most prominently in area 10 , anterior cingulate gyrus and supplementary motor cortex bilaterally (average reduction 14\%). The ${ }^{18} \mathrm{~F}-6$-fluorodopa scan suggested a decrease of cortical dopamine in the mesial frontal cortex but it is unlikely this had a significant effect on local CBF as this is generally normal in nondemented Parkinson's disease and in patients with striatonigral degeneration (Brooks et al., 1990; cf. Perlmutter and Raichle, 1985). The right amygdala was compromised and mild reductions of blood flow were found in the superior temporal gyri and in the left inferior parietal lobe. The flow reductions in these areas might be related to the interruption of auditory or closely associated pathways. Some support for this is provided by the MRI which depicted abnormal signals in the white matter just posterior and ventral to the putamen bilaterally. On routine examination, however, no hearing loss was obvious. Although the additional lesions complicate to some extent the explanation of the behavioural findings they do not prevent us from drawing our main conclusions.

Neither the patient's history nor the information obtained by the diagnostic interview provided evidence for the presence of incapacitating personality changes or psychiatric symptoms such as apathy or obsessions, compulsions or motor stereotypies as reported by others (see Introduction). 
The cognitive deficits of the patient were generally consistent with those found in patients with frontal lobe dysfunction. The most prominent frontal lobe-like deficits were found on the modified WCST, the attentional setshifting task and the Tower of London test. The lack of verbal fluency was inconsistent, her ability on the easier task of retrieving animal names being markedly superior to her rather inefficient retrieval of words beginning with the letters $\mathrm{A}$ and $\mathrm{S}$. A similar dissociation has been described in the "frontal syndrome" (Stuss and Benson, 1986). Her failure to complete the WCST, together with her failure at the extradimensional shift stage of the attentional set-shifting task, provide strong evidence of frontal lobe-like dysfunction. Both of these tasks measure the ability to form and change set. Frontal patients may fail the WCST for either or both of these reasons (Milner, 1964; Nelson, 1976). A recent study of the extradimensional shift task showed that the effects of frontal lobe damage were quite specific, as patients with unilateral damage to the temporal lobes or to the amygdala-hippocampus were as successful as controls at completing the task (Owen et al., 1991).

Perhaps the strongest evidence of frontal lobe-like dysfunction was found for the pattern of performance on the Tower of London task. She performed poorly even when compared with patients with frontal lobe lesions in terms of both her accuracy and the speed of thinking. Like frontal lobe patients (Owen et al., 1990), but unlike those with Parkinson's disease (Morris et al., 1988; Owen et al., 1992), she took significantly longer to think about the solutions subsequent to, but not in general prior to, the first move. The absence of significantly lengthened initial thinking time in the frontal group implies that these patients make the first move before they have successfully generated an appropriate solution to the problem. This behaviour could be considered to be impulsive although the slower movement times among the frontal lobe patients show that this "impulsivity" does not simply arise from a tendency to move more quickly. The possible impulsivity of patient $\mathrm{A}$ on this test was also matched by rather fast latencies to respond on the visuospatial constructional tasks, where her performance was also impaired. On the Tower of London test, she made a large number of invalid moves, consistent with the "rule-breaking" tendencies reported to occur in frontal patients (Milner, 1964).

Her performance on the Tower of London test has to be considered in the context of her weak spatial and digit spans and spatial working memory performance. Her short digit span is unlikely to have affected her planning performance, as Shallice (1982) has previously shown that suppressing verbal rehearsal fails to affect performance on this test. Although her spatial span was only 4 , indicating a possible deficiency in the ability to store and produce spatial sequences (i.e. of moves), it should have been sufficient for her to successfully tackle the four move problems, whereas she only correctly solved two out of four of these in the minimum number of moves.

Her very poor spatial working memory performance could also have handicapped her generation of problem solutions. This task has affinities with the subject-ordered memory tests employed by Petrides and Milner (1982) that are also sensitive to frontal lobe damage. Poor performance on such tasks may not necessarily reflect a pure mnemonic deficit. Owen et al. (1990) found that patients with frontal lobe damage used a very inefficient strategy for dealing with this task, which probably added to their memory load. This inefficiency was also very apparent in the performance of the patient.

Frontal lobe patients have also been reported to exhibit deficits in the learning of conditional associations of several forms (Petrides and Milner, 1982) and so it was not particularly surprising that the patient failed our conditional visuospatial task at the six item stage. Her inconsistency of retrieval in this learning task would be compatible with a role of the frontal cortex in memory retrieval processes.

On the other hand, the spectrum of the patient's deficits in visual memory and learning, including impaired recognition memory for patterns, faces and locations, is not immediately suggestive of frontal lobe or BG dysfunction, as such deficits commonly follow damage to the temporal lobe, including the hippocampus and amygdala (Milner, 1968; Warrington and James, 1967b; Mishkin, 1982). These results, however, are consistent with the evidence of damage to the right amygdala and the hypometabolism of the superior temporal gyri and the left inferior parietal lobe shown in the PET blood flow study.

The patient's cognitive impairments are by no means global, as she exhibits apparently normal linguistic and perceptual functions. On formal intellectual testing, she performs at an average level consistent with her premorbid level of functioning. Yet it is evident that while still able to function at an average level, she displays marked deficits in reasoning and thinking abilities. For example she is particularly bad at making the deductive steps that enable adequate performance on the Raven's matrices, in utilizing feedback effectively to change attentional set, in generating a strategy to ease the memory load on the working memory task and in planning ability on the Tower of London task. In the latter test, it is important to manipulate spatial representations to generate and test solutions. Her ability to manipulate spatial imagery was specifically found to be deficient in the computerized tests of visuospatial construction when she was required to make rotational and mirror image transformations, although her constructional ability per se was normal.

Although there have been relatively few detailed neuropsychological investigations of patients such as $\mathrm{A}$, with 
damage to the BG involving mainly the GPe and GPi, a paper of Laplane et al. (1989) reports eight cases with bilateral BG lesions showing frontal lobe-type syndromes. The main features were a decrease in spontaneous activity and drive with preservation of intellectual function. Like patient A, many also showed reductions in verbal fluency and difficulties in completing the WCST. Some exhibited disburbances in memory, particularly on tests of digit span. Laplane et al. also described "cognitive slowing" as a common feature of the syndrome, though without providing a quantitative assessment of this symptom. We found that patient A only showed cognitive slowing on one specific measure. Thus, like frontal lobe patients (Owen et al., 1990), she exhibited slower responses after generating the first move of attempted solutions of the Tower of London test but she was not slower to initiate this first move nor in her perceptual evaluation of a psychologically meaningful stimulus as assessed with the P300. Of all the cases described by Laplane et al. (1989), patient A most resembles Case 7. Like Case 7, she had a history of drug abuse, alcoholism and behavioural disorder. Case 7 had bilateral lesions primarily located in the GPe, although part of the GPi was also probably involved and showed decreases in glucose metabolism in the mediofrontal areas and in lateral regions at certain levels. In neuropsychological terms Case 7 showed impairments in attaining categories on the WCST, rather than making perseverative errors, a pattern of disability similar to that shown by A on a modified form of the test. Case 7 showed more deficits in verbal fluency than patient $A$, but apparently less severe impairment in digit span.

The detailed investigation of the patient has confirmed that a frontal lobe-type syndrome can follow damage to the $\mathrm{GP}$, as characterized by a combination of results obtained from neuropsychological testing and neuroimaging. It is most plausible to assume that the reduced blood flow, most prominently in area 10 and the anterior cingulate, is closely related to the expression of these cognitive deficits, but the question remains about the origin of the reduced blood flow. Reduction of CBF in the inferolateral and medial frontal cortex is reported following capsular genu infarction (Tatemichi et al., 1992). Although the authors assume that thalamofrontal projections are directly interrupted, the site of their lesions is in just the appropriate position to interrupt a major part of the pallido-thalamic projection from the medial globus pallidus (fasciculus lenticularis). However, despite the absence of frontal lobe, deep white matter or thalamic lesions on MRI and CT in our patient, we cannot refute entirely the possibility that some additional damage to thalamofrontal connections had occurred by gliosis of the internal capsule although its thickness seemed to be preserved. The combination of frontal hypometabolism and bilateral GP lesions has also been reported by Laplane et al. (1989), findings interpreted as the result of pallidal deafferentation.

Detailed knowledge of the neuronal circuitry of the BG makes it clear that there are intimate associations between the $\mathrm{BG}$ and frontal cortex, mediated in part by the presence of parallel, segregated cortico-striatal-pallidal-thalamocortical "loops" which have been postulated to fulfil distinct motor and cognitive functions (Alexander et al., 1986). Therefore, the patient's cognitive deficits may well arise from the disruption of processing of information centred on the anterior cingulate gyrus and area 10 by corticostriatal loops at the level of the GP. It is unclear how much the dopamine reduction in the mesial frontal areas, as measured by the ${ }^{18} \mathrm{~F}-6$-fluorodopa study, has added to these deficits. It seems most unlikely that the frontal lobelike syndrome she exhibits could be attributed to drug (including alcohol) abuse, as for example chronic alcoholics show a different pattern of deficits on the computerized tests (Joyce and Robbins, 1991).

Her failure in the tests we have used that are sensitive to frontal lobe dysfunction is consistent with the disruption of several different forms of processing. This contrasts sharply with the much more restricted cognitive deficits we have described using the same computerized tests on patients with Parkinson's disease. For example, unmedicated Parkinson's patients, early in the course, show impairments in extradimensional shifting, but not in the subject ordered test of spatial working memory or in any aspect of the Tower of London planning task (Downes et al., 1989; Owen et al., 1992). On the other hand, patients with multiple system atrophy, which is associated with widespread damage in the striatum, have a qualitatively similar, though milder spectrum of frontal lobe-type deficits on these tests than we have described here for patient A (Robbins et al., 1992). Although detailed comparisons are impossible the acute confusional episode at disease onset and the pattern of long-lasting behavioural and cognitive deficits resemble the effects of capsular genu infarction (Tatemichi et al., 1992). These complementary results are helping to refine former concepts such as "subcortical" or "frontosubcortical" dementia (Albert et al., 1974).

\section{Acknowledgement}

We are indebted to Mrs A for her cooperation throughout the course of this study. This work was supported by a Programme Award from the Wellcome Trust and a travel grant from CibaGeigy B.V. Arnhem.

\section{REFERENCES}

Albert M, Feldman RG and Willis AL (1974) The subcortical dementia of progressive supranuclear palsy. Journal of Neurology, Neurosurgery and Psychiatry 37, 121-130.

Alexander GE, Delong MR and Strick PL (1986) Parallel organization of functionally segregated circuits linking basal ganglia and cortex. Annual Reviews of Neuroscience 9, 357-381. 
Benton AL and Van Allen MW (1968) Impairment of facial recognition in patients with cerebral disease. Cortex, $\mathbf{4}$, 344-358.

Brooks DJ, Ibanez V, Sawle GV, Quinn N, Lees AJ, Mathias CJ, Bannister R, Marsden CD and Frackowiack RSJ (1990) Differing patterns of striatal ${ }^{18} \mathrm{~F}$-dopa uptake in Parkinson's disease, multiple system atrophy, and progressive supranuclear palsy. Annals of Neurology, 28, 547-555.

Coles MGH, Gratton G, Bashore TR, Eriksen CW and Donchin E (1985) A psychophysiological investigation of the continuous flow model of human information processing. Journal of Experimental Psychology, Human Perception and Performance, 11, 529-553.

Deelman BG and Saan RJ (1990) Memory deficits: assessment and recovery. In: Traumatic Brain Injury (Eds BG Deelman, RJ Saan and AH van Zomeren) pp. 49-76. Swets en Zeitlinger, Lisse.

Downes JJ, Roberts AC, Sahakian BJ, Evenden JL, Morris RG and Roberts TW (1989) Impaired extra-dimensional shift performance in medicated and unmedicated Parkinson's disease: evidence for a specific attentional dysfunction. Neuropsychologia, 27, 1329-1343.

Friston KJ, Passingham RE, Nutt JG, Heather JG, Sawle GV and Frackowiak RSJ (1989) Localisation in PET images: direct fitting of the intercommissural (AC-PC) line. Journal of Cerebral Blood Flow Metabolism, 9, 690-695.

Friston KJ, Frith CD, Liddle PF and Frackowiak RSJ (1991) Comparing functional (PET) images: The assessment of significant change. Journal of Cerebral Blood Flow Metabolism, in press.

Haaxma R, Van Boxtel A, Brouwer WH, Göeken LNH, Denier van der Gon JJ, Colebatch JG, Martin A, Brooks DJ, Noth J and Marsden CD (1991) Motor function in a patient with bilateral lesions of the globus pallidus. Submitted.

Joyce EM and Robbins TW (1991) Frontal lobe function in Korsakoff and non-Korsakoff alcoholics: Planning and spatial working memory. Neuropsychologia, 29, 709-723.

Lammertsma AA, Cunningham VJ, Deiber MP, Heather JD, Bloomfield PM, Nutt J, Frackowiak RSJ and Jones T (1990) Combination of dynamic and integral methods of generating reproducible functional CBF images. Journal of Cerebral Blood Flow Metabolism, 10, 675-686.

Laplane D, Baulac M, Widlocher D and Dubois B (1984) Pure psychic akinesia with bilateral lesions of basal ganglia. Journal of Neurology, Neurosurgery and Psychiatry, 47, 377-385.

Laplane D, Levasseur M, Pillon B, Dubois B, Baulac M, Mazoyer B, Tran Dinh S, Sette G, Danze F and Baron JC (1989) Obsessive-compulsive and behavioural changes with bilateral basal ganglia lesions. Brain, 112, 699-725.

Luteyn F and Ploeg van der FAE (1983) Handleiding van de Groninger Intelligentie Test. Swets en Zeitlinger, Lisse.

Luteyn F, Starren J and Dyk van H (1985) Nederlandse Persoonijkheids Vragenlijst. Swets en Zeitlinger, Lisse.

Milner B (1964) Some effects of frontal lobectomy in man. In: The Frontal Granular Cortex and Behaviour (Eds JM Warren and K Akert), pp. 313-334. McGraw Hill, New York.

Milner B (1968) Visual recognition and recall after right temporal lobe excision in man. Neuropsychologia, 6, 191-209.

Mishkin M (1982) A memory system in the monkey. In: The Neuropsychology of Cognitive Function (Eds DE Broadbent and L Weiskrantz), pp. 85-95. Royal Society, London.

Morris RG, Downes JJ, Evenden JL, Sahakian BJ, Heald A and Robbins TW (1988) Planning and spatial working memory in Parkinson's disease. Journal of Neurology, Neurosurgery and Psychiatry, 51, 757-766.

Nelson HE (1976) A modified card sorting test sensitive to frontal lobe defects. Neuropsychologia, 12, 313-324.
Nelson HE (1982) National Adult Reading Test Manual. NFERNelson, Windsor.

Newcombe F. Oxford Recurring Faces Test, unpublished.

Owen AM, Downes JJ, Sahakian BJ, Polkey CE and Robbins TW (1990) Planning and spatial working memory following frontal lobe lesions in man. Neuropsychologia, 28, 1021-1034.

Owen AM, Roberts AC, Polkey CE, Sahakian BJ and Robbins TW (1991) Extra-dimensional versus intra-dimensional set shifting performance following frontal lobe excisions, temporal lobe excisions or amygdalo-hippocampectomy in man Neuropsychologia, 29, 993-1006.

Owen AM, James M, Leigh PN, Summers BA, Marsden CD, Quinn NP, Lange K and Robbins TW (1992) Fronto-striatal cognitive deficits at different stages of Parkinson's disease. Brain, 115, 1727-1751.

Perlmutter JS and Raichle ME (1985) Regional blood flow in hemiparkinsonism. Neurology, 35, 1127-1134.

Petrides M and Milner B (1982) Deficits on subject-ordered tasks after frontal and temporal lobe lesions in man. Neuropsychologia, 20, 249-262.

Pritchard WS (1981) Psychophysiology of P300. Psychological Bulletin, 89, 506-540.

Rachman S and Hodgson RJ (1980) Maudsley Obsessive Compulsive Inventory. Prentice Hall, Englewood Cliffs, NJ.

Raven JC (1958) Standard Progressive Matrices. HK Lewis \& Co. Ltd, London.

Robbins TW, James M, Lange K, Owen A, Quinn NS and Marsden CD (1992) Cognitive performance in multiple system atrophy. Submitted.

Sahakian BJ, Morris RG, Evenden JL, Heald A, Levy R, Philpot $M$ and Robbins TW (1988) A comparative study of visuospatial memory and learning in Alzheimer type dementia and Parkinson's disease. Brain, 111, 695-718.

Shallice T (1982) Specific impairments in planning. In: The Neuropsychology of Cognitive Function (Eds DE Broadbent and L Weiskrantz), pp. 199-209. The Royal Society, London.

Strub RL (1989) Frontal lobe syndrome in a patient with bilateral globus pallidus lesions. Archives of Neurology, 46, 1024-1027.

Stuss DT, Benson DF (1986) The Frontal Lobes. Raven Press, New York.

Talairach J and Tournoux P (1988) Co-Planar Stereotaxic Atlas of the Human Brain: 3-Dimensional Proportional System: an Approach to Cerebral Imaging. Georg Thieme, Stuttgart.

Tatemichi TK, Desmond DW, Prohovnik I, Cross DT, Gropen TI, Mohr JP and Stern Y (1992) Confusion and memory loss from capsular genu infarction. Neurology, $\mathbf{4 2}$, 1966-1979.

Warrington EK (1984) Recognition Memory Test. NFER Nelson, Windsor.

Warrington EK and James M (1967a) Disorders of visual perception in patients with localized cerebral lesions. Neuropsychologia, 5, 253-266.

Warrington EK and James M (1967b) An experimental investigation of facial recognition in patients with unilateral cerebral lesions. Cortex, 3, 317-326.

Warrington EK and James M (1988) Visual apperceptive agnosia. A clinico-anatomical study of three cases. Cortex, $\mathbf{2 4}$ 13-32.

Warrington EK and Taylor A (1973) The contribution of the right parietal lobe to object recognition. Cortex, 9, 152-164.

Wechsler D (1955) Wechsler Adult Intelligence Scale Manual. Psychological Corporation, New York.

(Received 30 September 1993; accepted 17 October 1993) 


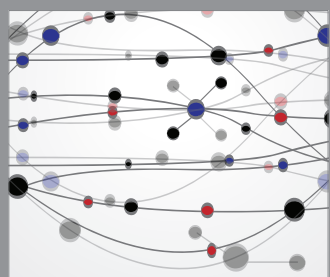

The Scientific World Journal
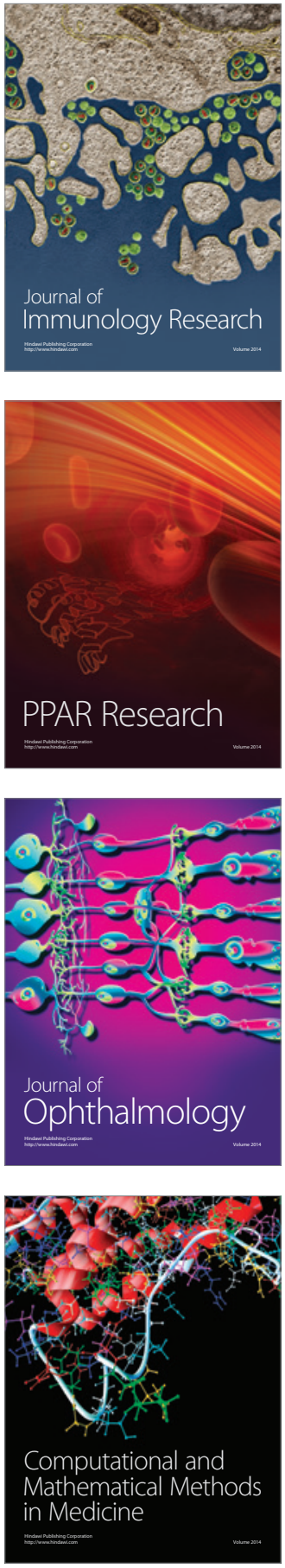

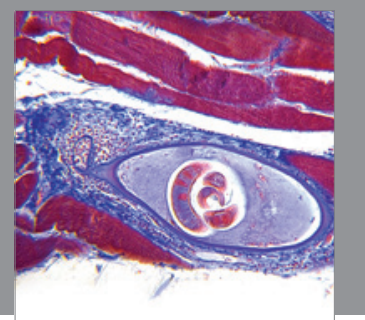

Gastroenterology

Research and Practice
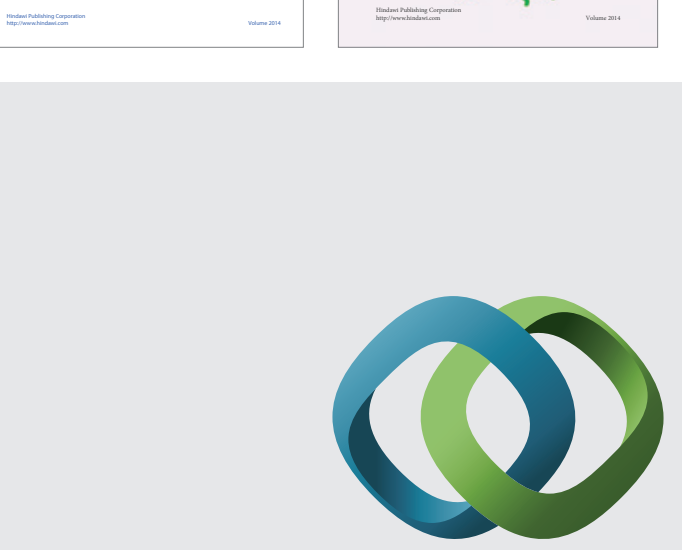

\section{Hindawi}

Submit your manuscripts at

http://www.hindawi.com
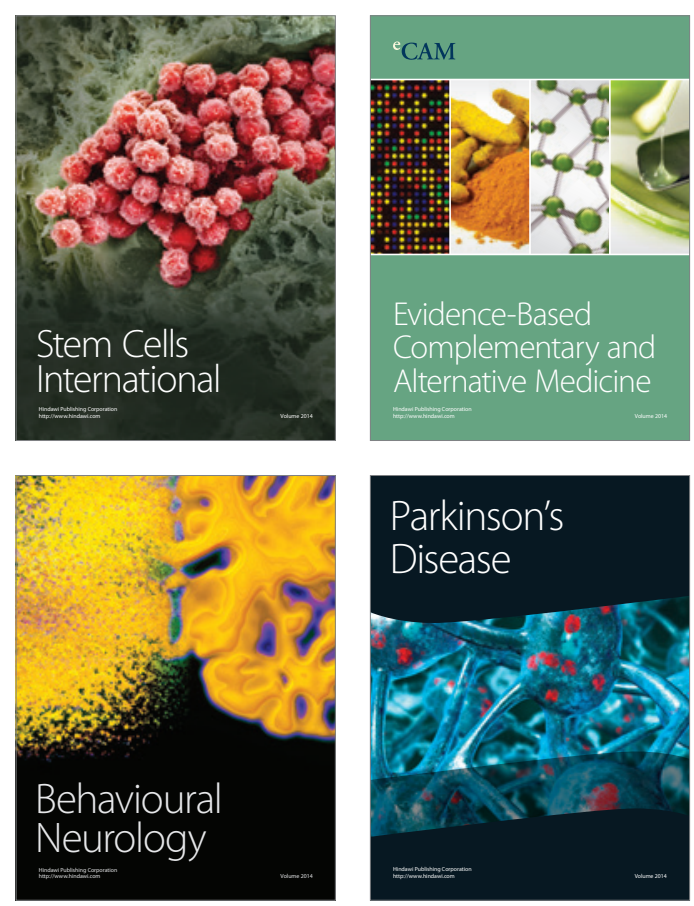

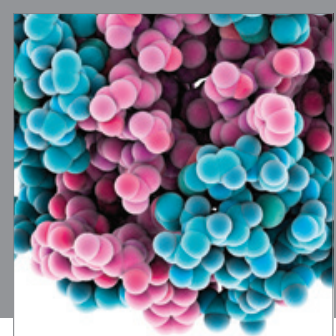

Journal of
Diabetes Research

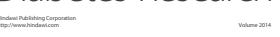

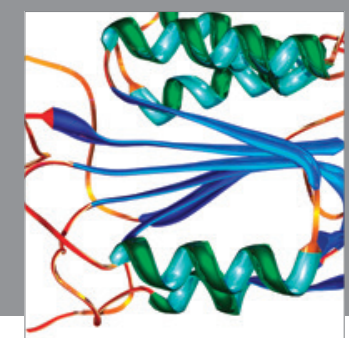

Disease Markers
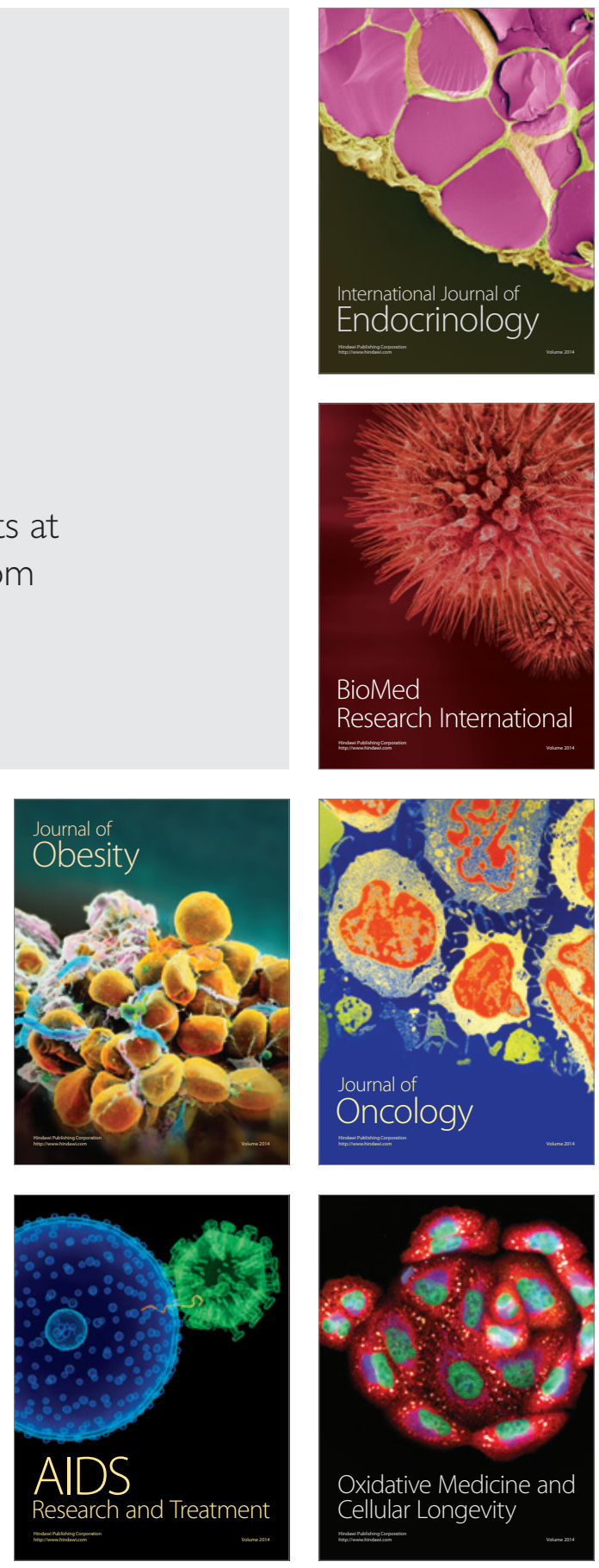